\title{
Changes in the influence of the western Pacific subtropical high on Asian summer monsoon rainfall in the late 1990s
}

\author{
Yanyan Huang ${ }^{1}$ Bin Wang ${ }^{2,3} \cdot$ Xiaofan $\mathrm{Li}^{4} \cdot$ Huijun Wang ${ }^{1,5}$
}

Received: 19 March 2017 / Accepted: 21 September 2017 / Published online: 20 October 2017

(C) The Author(s) 2017. This article is an open access publication

\begin{abstract}
The Year-to-year variability of the western Pacific subtropical high (WPSH) is primarily controlled by atmosphere-ocean interaction (AOI) between the WPSH and the Indo-Pacific warm pool dipole SST anomalies (AOI mode) and the anomalous SST forcing from the equatorial central Pacific (the CP forcing mode). In this study, we show that the impacts of the WPSH variability on Asian summer monsoon rainfall have changed after the late 1990s. Before the late 1990s (the PRE epoch), the WPSH primarily affects East Asian summer monsoon (EASM) and had little influence on Indian summer monsoon (ISM), whereas after the late 1990s (the POST epoch), the WPSH has strengthened its linkage to the ISM while weakened its relationship
\end{abstract}

Yanyan Huang

huangyy@nuist.edu.cn

1 Collaborative Innovation Center on Forecast and Evaluation of Meteorological Disasters/Collaborative Innovation Center on Forecast and Evaluation of Meteorological Disasters/Joint International Research Laboratory of Climate and Environment Change/Key Laboratory of Meteorological Disaster, Ministry of Education, Nanjing University of Information Science and Technology, 210044 Nanjing, China

2 Department of Atmospheric Sciences and International Pacific Research Center, School of Ocean and Earth Science and Technology, University of Hawaii, Honolulu, HI 96822, USA

3 Earth System Modeling Center, Nanjing University of Information Science and Technology, 210044 Nanjing, China

4 School of Earth Science, Zhejiang University, Hangzhou 310027, China

5 Nansen-Zhu International Research Centre, Institute of Atmospheric Physics, Chinese Academy of Sciences, 100029 Beijing, China with the EASM. This epochal change is associated with a change in the leading circulation mode in the Asia-WP region. During the PRE (POST) epoch the WPSH variation is mainly controlled by the AOI (CP forcing) that mainly affects EASM (ISM). The epochal change of the leading mode may be attributed to the change of the ENSO properties in late 1990s: the CP types of El Nino become a leading ENSO mode in the POST epoch. This work provides a new perspective for understanding decadal changes of the ENSOmonsoon relationship through subtropical dynamics.

\section{Introduction}

The important role of the western Pacific subtropical high (WPSH) in affecting Asian summer climate has been noticed for many years. As a crucial component of East Asian summer monsoon (EASM) (Tao 1963; Lau and Li 1984; Ding 1994), the intensity, shape and location of the WPSH dominate the large-scale quasi-stationary frontal zones in East Asia (Tao and Chen 1987; Chang et al. 2000; Wang et al. 2001; Lu et al. 2016). Meanwhile, the WPSH shows a significant influence on Indian summer climate by affecting the intensity of Indian summer monsoon (ISM) with the easterlies at its southern edge (Wang and Fan 1999; Lau et al. 2000).

Efforts have been devoted to explaining the formation and variability of the WPSH. The role of the Tibetan Plateau (Ye and Gao 1979; Ye and Wu 1998; Lee et al. 2015), monsoon diabatic heating (Hoskins 1996; Rodwell and Hoskins 2001), and land-sea heating contrast (Wu and Liu 2003; Miyasaka and Nakamura 2005) has been investigated. Meanwhile, because the ocean acts as an immense energy source in summer, the critical role of the sea surface temperature anomalies (SSTA) has received considerable attention for many 
years (e.g., Huang and Wu 1989; Lu and Dong 2001; Zhou and Wang 2006).

Recently, based upon previous work and their own numerical experiments, Wang et al. (2013) (hereafter W13) have identified two different major SSTA mechanisms governing the two-leading empirical orthogonal function (EOF) modes of the interannual variability of low-level circulation in the Asian-western Pacific domain. Both modes represent the WPSH variability, and the mechanisms regulating these modes are illustrated in Fig. 1. The atmosphere-ocean interaction between the WPSH and SST dipole pattern [northern Indian Ocean (NIO) warming and western north Pacific
(WNP) cooling] is suggested to be responsible for the EOF1 mode. This is because the strong and westward extension of WPSH can influence the SSTA over WNP/NIO by strengthening/weakening mean state winds and induce WNP cooling/NIO warming. The WNP cooling/NIO warming can in turn strengthen the WPSH through changing in situ precipitation/tropospheric temperature and hence generating atmospheric descending Rossby/warm Kelvin waves (e.g., Wang et al. 2000; Yang et al. 2007; Li et al. 2008; Xie et al. 2009; Du et al. 2009; Xiang et al. 2011). The equatorial central Pacific cooling governs the WPSH EOF2 mode by shifting the rising limb of Walker cell westward, thus causing

(a) EOF1: Atmosphere-Ocean Interaction (AOI) mode

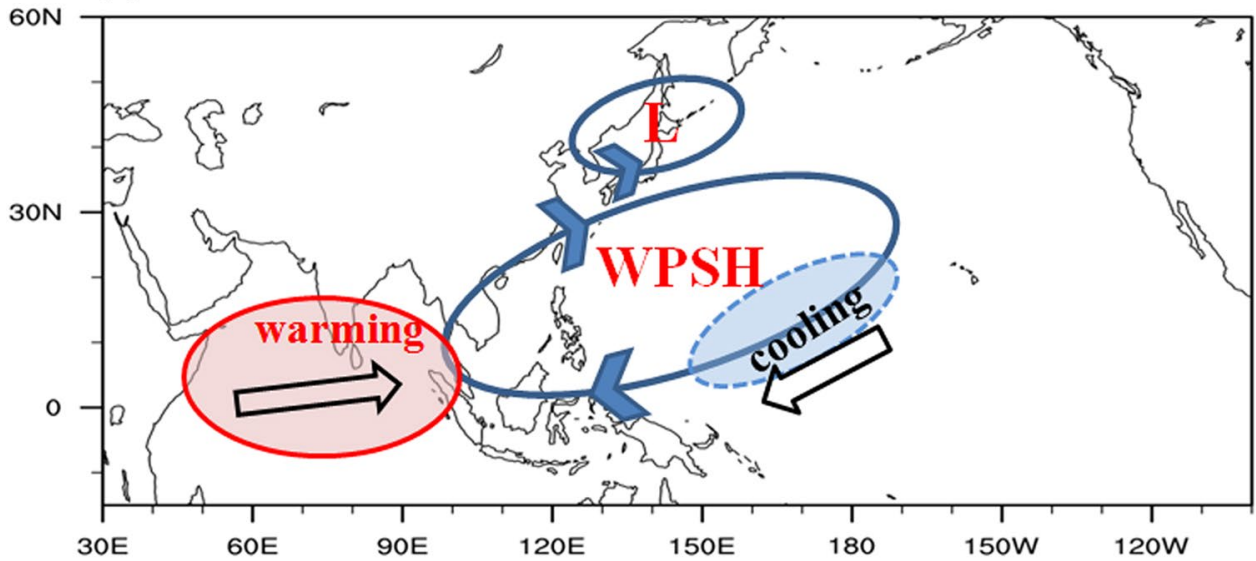

(b) EOF2: Equatorial Central Pacific forcing (CP forcing) mode

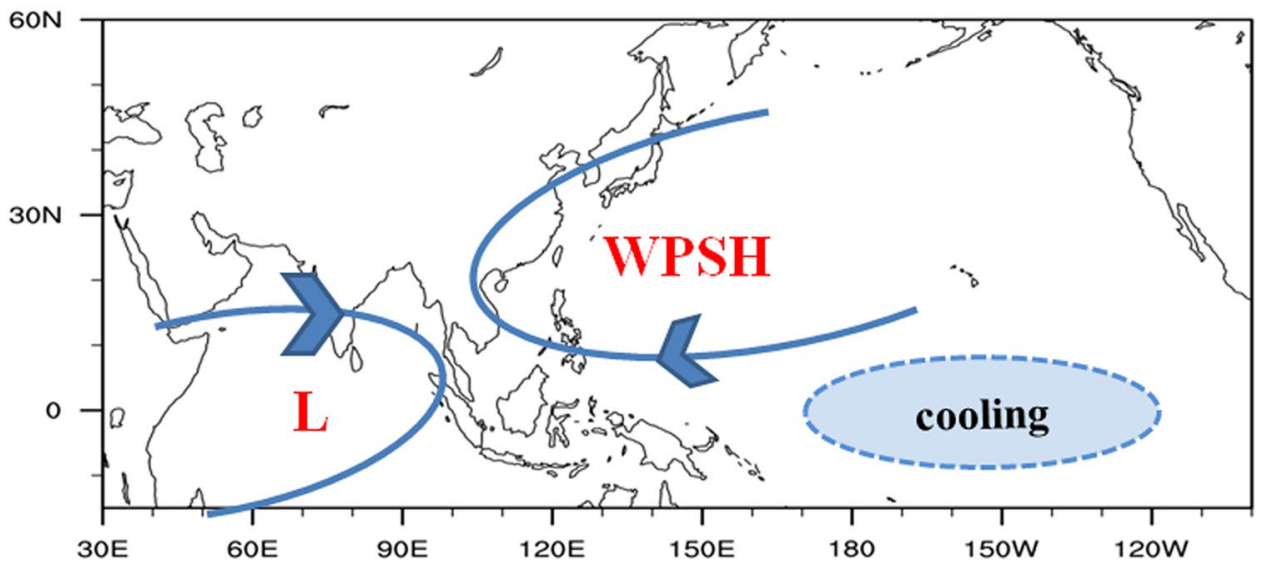

Fig. 1 The pronounced characteristic of the EOF modes in the Asian-western Pacific low-level circulation and the responsible SSTA mechanism for the WPSH variability. The EOF1 mode which features an intense high over western Pacific (solid circle with "WPSH" inside) and a low over Japan (solid circle with "L" inside) is governing by the atmosphere-ocean interaction between the WPSH and the underlying SST dipole (warming over the northern IO and cooling over the WNP) (a). The sum of the anomalous winds and the mean winds (denoted by the double open arrows) results in enhanced (reduced) total wind speed that cools (warms) the WNP (northern IO). However, the cooling in the WNP suppresses convection, which, in turn, generates descent atmospheric Rossby waves, thus strength- ening the WPSH. The warming in the northern IO also favors an enhanced WPSH by generating an anticyclonic vorticity associated with an atmospheric Kelvin wave response to the east of northern IO warming (same as the Figure S7 in W13). The EOF2 mode with a high over western Pacific (solid curve with "WPSH" inside) and a low over Indian ocean (solid curve with "L" inside) is forced by the equatorial central Pacific cooling (b). The central Pacific cooling shifts the rising limb of Walker cell westward, therefore reducing convection around $160 \mathrm{E}$ and increasing convection over the maritime continent. The suppressed convection (enhanced convection) strengthens the WPSH by emanating descending Rossby waves (offequatorial anticyclonic shear vorticity) 
convection anomalies over the western Pacific/Maritime Continent which further emanate descending Rossby waves/ off-equatorial anticyclonic shear vorticity (e.g., Wang et al. 2003; Chung et al. 2011; He et al. 2015).

Moreover, multi-decadal variation of Asian summer climate in recent decades has been noticed (e.g., Wang 2001; Jiang and Wang 2005; Wang et al. 2008; Fan et al. 2008; Huang et al. 2013, 2015; Huang and Li 2015; Xu et al. 2015; Zhu et al. 2011). Particularly, many studies have found the significant decadal shift of the interannual variability of Asian summer climate in the 1990s. Kwon et al. (2005) revealed that the leading mode of summer precipitation over the East Asia and western North Pacific region has changed in the middle 1990s, which is attributed to the central role of the equatorial central Pacific SSTA after the middle 1990s (Yim et al. 2008). Feng et al. (2014) studied the modulation of the Pacific decadal oscillation (PDO) in different phases on the behavior of the EASM in El Nino decaying years. Jin et al. (2016) found that a decadal shift in ENSO teleconnection over the western Pacific impacts the Eastern China precipitation dipole after the middle 1990s. In terms of the WPSH, although He and Zhou (2015) noticed the different role of the SSTA in affecting the WPSH variability in the early 1990s, the specific mechanism is unclear, and the possible decadal shift of the WPSH-associated influence hasn't been studied. Therefore, we examine the decadal shift of the WPSH's influence on Asian summer climate and investigate the possible mechanism in this study.

Our analysis of observations confirms that such decadal changes take place. After the late 1990s, the WPSH has increased influences on the ISM and weakened effects on the EASM. This decadal change is associated with the changed leading EOF mode of the WPSH. The equatorial central Pacific SSTA has become a major forcing to the WPSH after the late 1990s, causing the change of the leading mode. These findings have important implications for Asian summer monsoon prediction. The rest of the paper is organized as follows. Section 2 introduces the data and method. Section 3 shows the decadal change in the WPSH influence on the Asian summer climate in the late 1990s. The decadal change of the primary EOF mode of the low-level AsianPacific circulation after the late 1990s is revealed in Sect. 4. Section 5 investigates the contribution of the upper-level circulations. The possible mechanism is discussed in Section 6. Section 6 summarizes the results.

\section{Data and method}

The monthly mean datasets used in this study are geopotential height, zonal and meridional winds derived from the National Centers for Environmental Prediction (NCEP)/Department of Energy (DOE) AMIP-II Reanalysis
(Kanamitsu et al. 2002), the precipitation from Global Precipitation Climatology Project V2.3 (Adler et al. 2003) and the sea surface temperature from the National Oceanic and Atmospheric Administration (NOAA) Extended Reconstructed SST Version 3b (ERSST V3b) (Smith et al. 2008). In terms of the monsoon rainfall index, the Indian summer monsoon rainfall index (ISMRI) and the Yangtze River rainfall index (YRRI) are chosen to represent the Indian summer monsoon rainfall and the east Asian summer monsoon rainfall, respectively. Here ISMRI/YRRI is calculated as the regionally averaged precipitation over $\left(10^{\circ}-30^{\circ} \mathrm{N}\right.$, $\left.72^{\circ}-85^{\circ} \mathrm{E}\right) /\left(28^{\circ}-34^{\circ} \mathrm{N}, 106^{\circ}-122^{\circ} \mathrm{E}\right)$.

The summer mean (June-July-August) record during 1979-2016 is analyzed in this study. In order to focus on the interannual variability associated with the WPSH, all involved datasets during 1979-2016 have been de-trended before the analysis. The statistical significance is assessed using the Student's $t$ test. It should be noted that the influence of the autocorrelation on the freedom degree has not been considered, because of the short record in this study.

\section{Changes in the WPSH's influence on the Asian summer climate}

To quantify the year-to-year variability of the WPSH, following W13, a WPSH index (WPSHI) is defined by the regionally averaged $\mathrm{H} 850$ over the climatological maximum interannual variability center $\left(15^{\circ}-25^{\circ} \mathrm{N}, 115^{\circ}-150^{\circ} \mathrm{E}\right)$. The normalized summer WPSHI during 1979-2016 is shown in Fig. 2.

The close relationship between WPSHI and the principal components (PCs) of the EOF modes for the 850-hPa geopotential height (H850) over the Asian-Australian monsoon domain has been discussed in W13. However, we find a decadal shift in the relationship between WPSHI and PCs in this study. Figure 3 displays the 13-years running

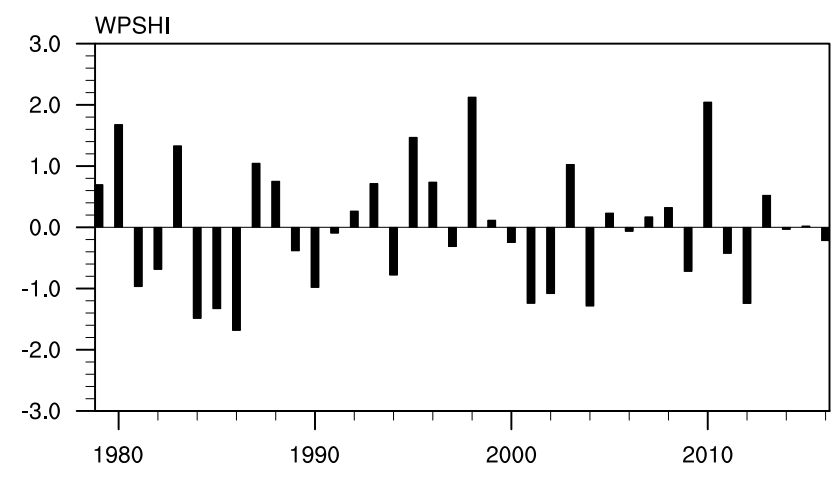

Fig. 2 The normalized JJA WPSH index during 1979-2016 which is defined by the regionally averaged $850-\mathrm{hPa}$ geopotential height over $\left(15^{\circ} \mathrm{N}-25^{\circ} \mathrm{N}, 115^{\circ} \mathrm{E}-150^{\circ} \mathrm{E}\right)$ 


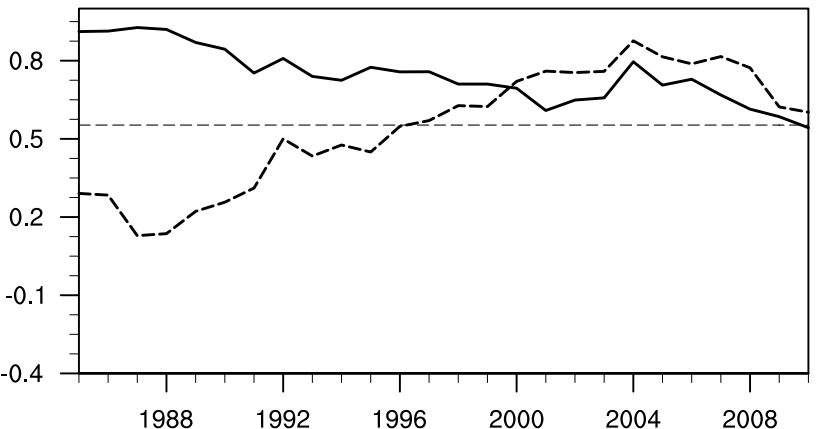

Fig. 3 13-year running correlation of WPSHI with PC1 (thick solid line) and PC2 (thick dash line) of the EOF modes for the JJA 850$\mathrm{hPa}$ geopotential height over the Asian-Australian monsoon domain $\left(20^{\circ} \mathrm{S}-40^{\circ} \mathrm{N}, 30^{\circ} \mathrm{E}-180^{\circ} \mathrm{E}\right)$ during $1979-2016$, in which the thin dash line denotes the $95 \%$ confidence levels

correlation of WPSHI with PC1 and PC2 of H850, respectively. Compared with the weakening trend in the correlation of the WPSHI with PC1, it is noteworthy that the correlation between the WPSHI and PC2 increases steadily and exceeds the correlation between the WPSHI and PC1 after the late 1990s. Considering the different spatial patterns between EOF-1 mode and EOF-2 mode (W13), the high correlation of the WPSHI with PC2 after the late 1990s implies that the spatial pattern reflected by the WPSHI and the associated influences may have changed after the late 1990s. Therefore, we compare the WPSH's influence during 1979-1999 (PRE epoch) with that during 2000-2016 (POST epoch) and discuss the possible mechanism in the following part.

Figure 4 shows the circulation pattern reflected by WPSHI and the associated climate anomalies during the PRE and POST epochs, respectively. During the PRE epoch, a positive WPSHI reflects a high pressure circulation in the western Pacific and a low pressure circulation over Japan, reminiscent of Pacific-Japan (PJ) pattern (Nitta 1987) or East Asia-Pacific (EAP) pattern (Huang and Sun 1992), which is associated with suppressed convection in the tropical western North Pacific and enhanced convection extending from the Yangtze River valley to Japan. Meanwhile, there is no significant rainfall signal in the India Peninsula (Fig. 4a). However, after the late 1990s (Fig. 4b), associated with a
Fig. 4 Correlation of the JJA WPSHI with the JJA precipitation (shading), 850-hPa geopotential height (contours) during 1979-1999 (a) and 2000-2016 (b). The light, medium and dark shading indicates the significant above 90 , 95 and $99 \%$ confidence levels, respectively (a) PRE

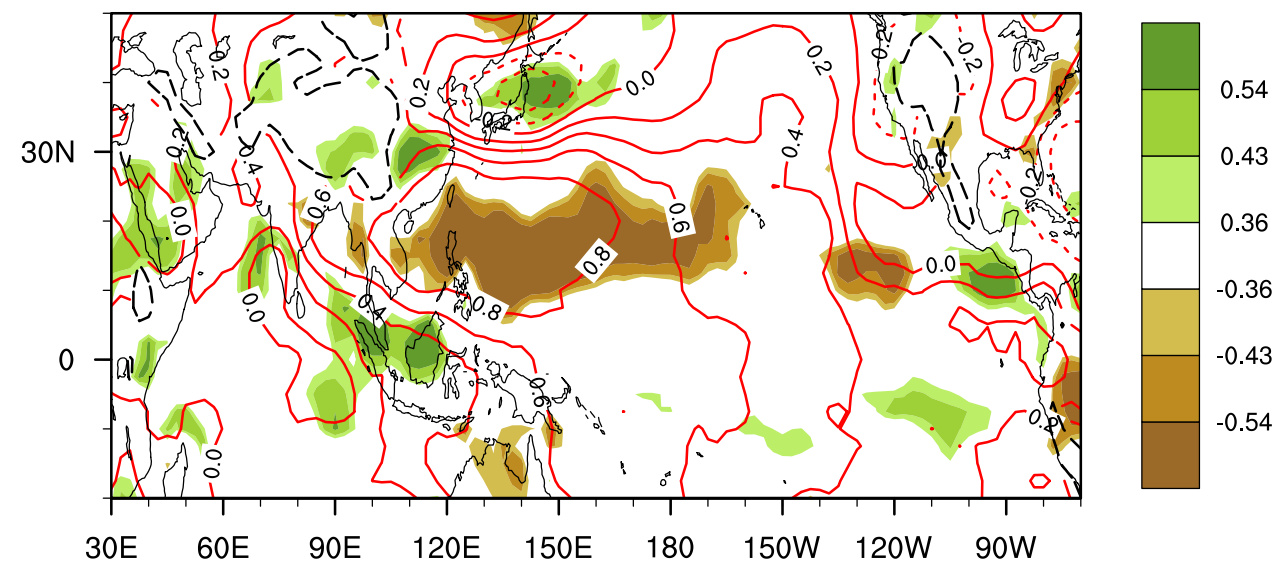

(b) POST

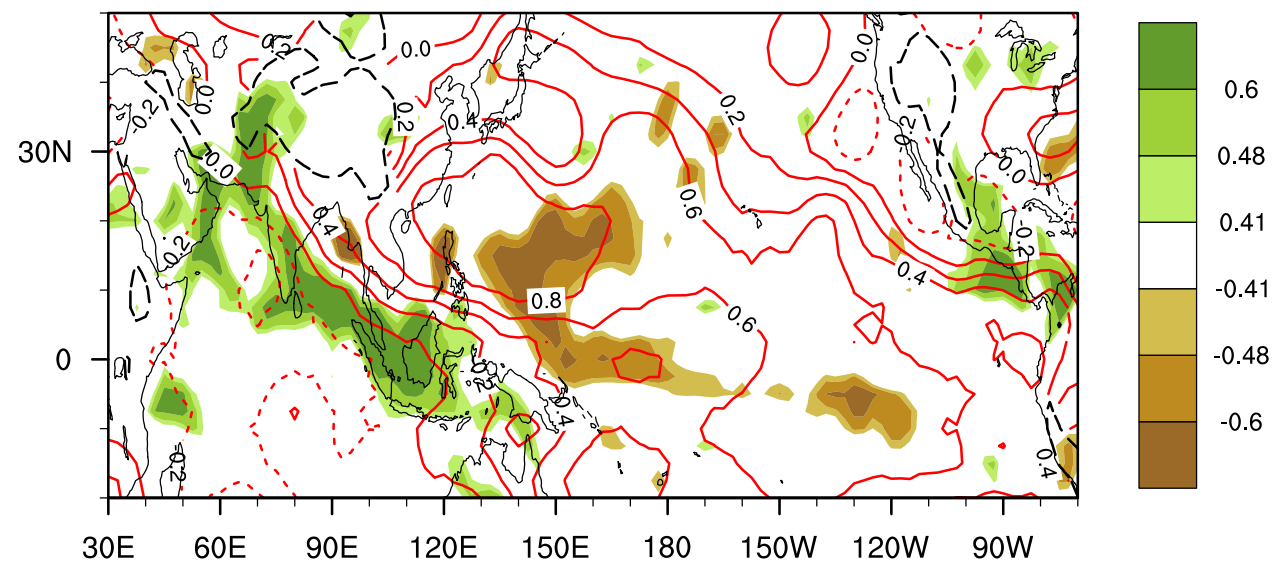


positive WPSHI, there is a large subtropical high extending from the western Pacific to northern Asia and a low pressure circulation over the Indian Ocean, concurring with the enhanced convection in the southeast flank of subtropical high along the rain band stretching from the Maritime Continent to India and the reduced convection over the Philippine Sea and the equatorial western Pacific. Influence of the WPSH on East Asia obviously weakens with the absence of the Japan low during the POST epoch.

To quantitatively investigate the decadal change of the WPSH's influence on Asian summer climate, we calculate the correlation coefficient (CC) of WPSHI with the ISMRI and the YRRI during PRE and POST epochs, respectively (Table 1 ). With a CC of -0.02 between WPSHI and ISMRI, the ISM is not linked to the WPSH during the PRE epoch. However, the CC between WPSH and ISMRI increases to 0.58 during POST epoch (significant at $95 \%$ confidence level), indicating the increasing association of the WPSH with the ISM after the late 1990s. Meanwhile, the WPSH is closely related with YRRI with a CC of 0.67 during 1979-1999 (significant at 99.9\% confidence level); but after the late 1990s, the CC between WPSHI and YRRI decreases to 0.40 , which is apparently lower than the PRE epoch CC, and the statistical significance drops below the $90 \%$ confidence level. It suggests that the influence of the WPSHI on the EASM has weakened after the late 1990s. Briefly, compared to the significant influence of the WPSHI on the EASM during the PRE epoch, the WPSHI is more closely related with the ISM during the POST epoch.

Overall, associated with different circulation patterns, the influences of the WPSH on Asian summer climate have a decadal change after the late 1990s. The WPSH's influence on the EASM has weakened and the relationship between the WPSH and the ISM becomes significant after the late 1990s.

\section{Change of the leading modes of Asian-western Pacific circulation}

To understand why the influence of WPSH on Asian monsoon rainfall changed after the late 1990s, we investigate

Table 1 The correlation coefficient of the JJA WPSHI with JJA ISMRI and JJA YRRI during PRE and POST epochs

\begin{tabular}{lll}
\hline & PRE (1979-1999) & $\begin{array}{l}\text { POST } \\
(2000- \\
2016)\end{array}$ \\
\hline ISMRI & -0.02 & $\mathbf{0 . 5 8}$ \\
YRRI & $\mathbf{0 . 6 7}$ & 0.40 \\
\hline
\end{tabular}

Boldface numbers are significant at the $95 \%$ confidence level whether the leading modes of Asian-western Pacific $850 \mathrm{hPa}$ geopotential (H850) circulation have changed.

To begin with, we examine the two leading EOF modes of the H850 during the entire period of 1979-2016 (Fig. 5). The EOF- 1 with a percent variance of $31.2 \%$ is characterized by an intense high pressure system extending from the western Pacific to the Indian Ocean and a low pressure system located over Japan, which concurs with suppressed rainfall over the South China Sea to the western North Pacific and enhanced rainfall over the region from the middle and lower reach of the Yangtze River valley to Japan (Fig. 5a). In the correlation map of the SSTA and 850-hPa winds (Fig. 5c), anomalous northeasterlies associated with cold SSTA over the western Pacific around $160^{\circ} \mathrm{E}$ and anomalous easterlies accompanied by warming over the northern Indian Ocean are observed. The positive feedback between the WPSH and underlying dipolar SST anomaly in Indo-western Pacific warm pool has been demonstrated to play a central role in sustaining the above circulation pattern by W13 (also see Fig. 1a).

The spatial pattern of the EOF-2 mode features a dipole pattern with a high pressure system over the Pacific and a low pressure system over the Indian Ocean, which are associated with enhanced rainfall on the southwest flank of the high pressure circulation and suppressed rainfall extending from the Philippine Sea southeastward to the equatorial western Pacific (Fig. 5b). The main feature of the associated SST anomaly is the significant negative SST anomaly over the equatorial central Pacific (Fig. 5d). The numerical experiment in $\mathrm{W} 13$ has demonstrated that the equatorial central Pacific cooling is responsible for the formation of the spatial pattern of EOF-2 (See Fig. 1b).

Note that the results in Fig. 5 show that the EOF 1 and EOF 2 are, respectively, more tightly linked to precipitation over the EA subtropical front and Indian summer monsoon (Table 2).

As we showing in Fig. 3, there is a decadal change in the relationship between WPSHI and PCs after the late 1990s. Meanwhile, comparing Figs. 4 and 5, the precipitation pattern associated with the WPSHI during the PRE epoch in Fig. 4a resembles the corresponding spatial patterns of EOF-1 mode in Fig. 5a, but the POST WPSHI reflects a precipitation pattern similar to that of the EOF-2 mode in Fig. 5b. This motivates us to further examine the leading circulation modes during the PRE and POST period.

Figure 6 shows that during the PRE epoch, the atmospheric-ocean interaction in Indo-Pacific warm pool sustains an intense high pressure system extending from the Pacific to the Indian Ocean and the PJ pattern along Asian coast, which resembles the spatial pattern of EOF-1 mode in the entire period of 1979-2016. However, after the late 1990s, with the equatorial central Pacific cooling becoming the major player, the center of the high pressure system moves 


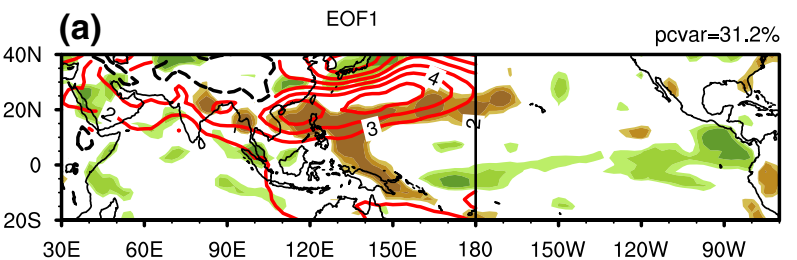

(c)

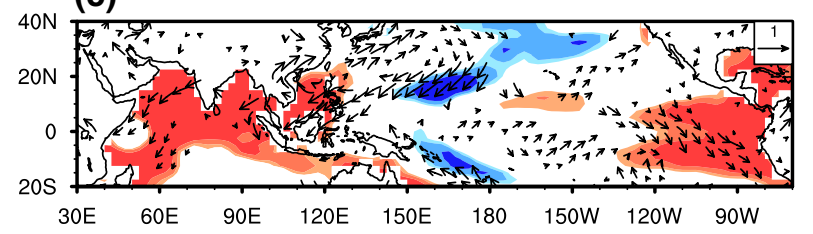

(e) $\mathrm{PC} 1$

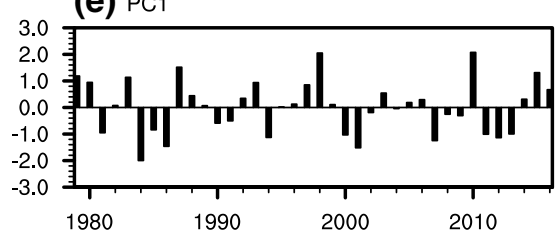

Fig. 5 The EOF-1 mode (left-side panels of a, c, e) and the EOF-2 mode (right-side panels of b, d, f) during 1979-2016. a The spatial pattern of the leading EOF mode derived from JJA 850-hPa geopotential height ( $\mathrm{m}$; contours) over the Asian-Australian monsoon domain $\left(20^{\circ} \mathrm{S}-40^{\circ} \mathrm{N}, 30^{\circ} \mathrm{E}-180^{\circ} \mathrm{E}\right)$ during $1979-2016$ and the correlated precipitation ( $\mathrm{mm} \mathrm{day}^{-1}$; shading) over the Indo-Pacific domain with the PC of EOF-1. The percent variance for the EOF-1 is given

Table 2 The correlation coefficient of the PC1 and PC2 with JJA ISMRI and JJA YRRI during 1979-2016, respectively

\begin{tabular}{ccc}
\hline & ISMR & YRRI \\
\hline PC1 & -0.15 & $\mathbf{0 . 4 4}$ \\
PC2 & $\mathbf{0 . 5 4}$ & 0.22 \\
\hline
\end{tabular}

Boldface numbers are significant at the $95 \%$ confidence level

eastward and northward and a relatively low pressure system appears in the northern Indian Ocean. A dipole geopotential height pattern resembles the spatial pattern of EOF-2 mode during 1979-2016. Actually, the pattern correlation of the POST EOF-1 mode with the EOF-2 mode in the entire period is 0.96 , but only is 0.28 with the EOF- 1 mode in the entire period. Similarly, the spatial pattern of the PRE EOF-1 mode resembles the spatial pattern of the EOF-1 mode in the entire period (1979-2016), as evidenced by the pattern correlation coefficient of 0.95 (0.50) with the EOF-1 (EOF-2) mode in the entire period.

The above evidence suggests that with the equatorial central Pacific cooling acting as the major forcing, the EOF-2 mode of H850 in the entire period has become the EOF-1 mode after the late 1990s. It also explains the higher CC between PC2 in the entire period and WPSHI after the late 1990s, and the decreased CC in the entire period between PC1 and WPSHI, although the latter still shows high

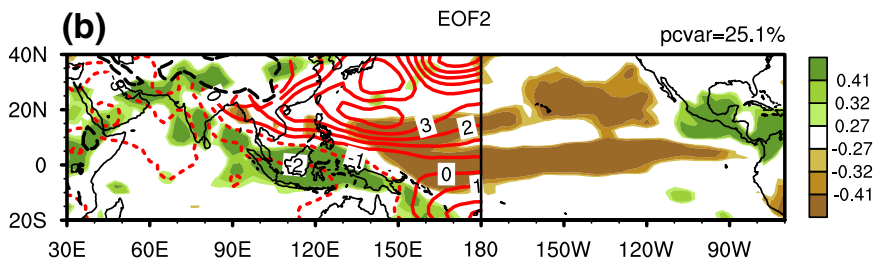

(d)
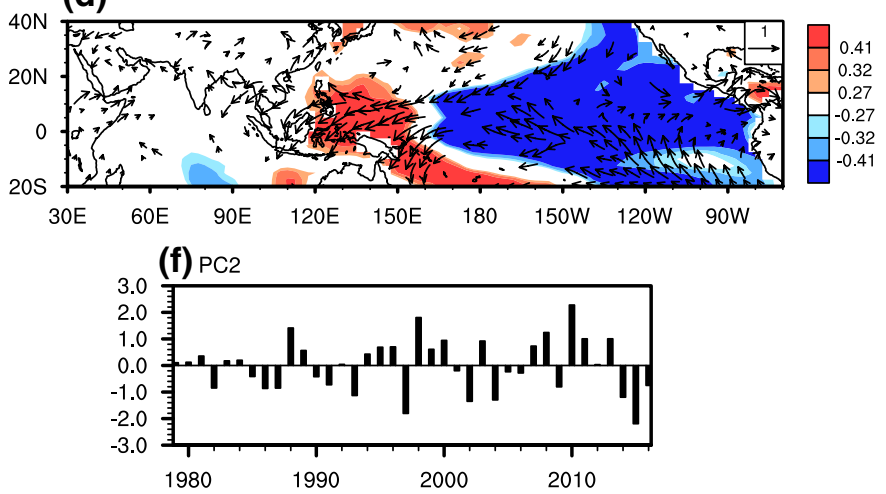

at the upper right corner of the panel. c The correlated SSTA (shading) and $850-\mathrm{hPa}$ horizontal winds $\left(\mathrm{ms}^{-1}\right)$ with reference to the $\mathrm{PC}$ of EOF-1 during 1979-2016. The light, medium and dark shading in Panels a-d indicates the correlations significant above 90, 95 and 99\% confidence levels, respectively. e Standardized time series of EOF-1 (PC) during 1979-2016. Panels of $\mathbf{b}, \mathbf{d}$ and $\mathbf{f}$ are the same as in $\mathbf{a}, \mathbf{c}$ and $\mathbf{e}$, respectively, but for the EOF-2 mode

statistical significance after the late 1990 s, possibly due to the large explained percent variance (Fig. 3).

In sum, the WPSHI reflects different leading circulation modes during the two epochs, and the change of the lowlevel leading circulation mode from PRE to POST epoch has caused the decadal change in the WPSH influence on Asian summer monsoon rainfall anomalies.

\section{Changes of the upper-level circulations associated with the WPSHI}

Considering the Asian summer monsoon variability is also closely related to the upper level circulation anomalies, we examine the changes of the upper-level circulations in this section.

The WPSH in the lower troposphere and the East Asian jet stream (EAJS) in the upper troposphere are the two dominant components of the EASM circulation system. Lin et al. (2010) found a decadal shift in the relationship between EAJS and WPSH after the late 1970s. Here, we calculate the CCs between WPSHI and EAJS index (EAJSI) during the two epochs. Following Lin et al. (2010), the EAJSI is defined as the PC time series of the leading EOF mode of zonal winds at $200 \mathrm{hPa}$ over $\left(20^{\circ} \mathrm{N}-60^{\circ} \mathrm{N}, 120^{\circ} \mathrm{E}-150^{\circ} \mathrm{E}\right)$ (Fig. 7). We find a decadal shift in the relationship between 


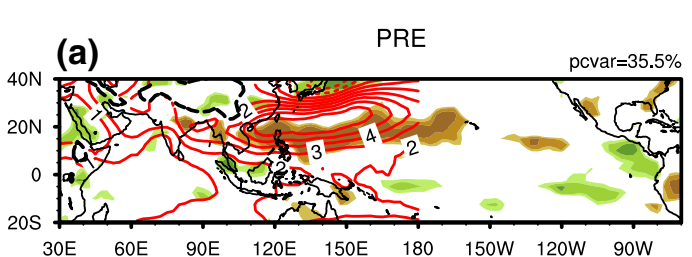

(c)

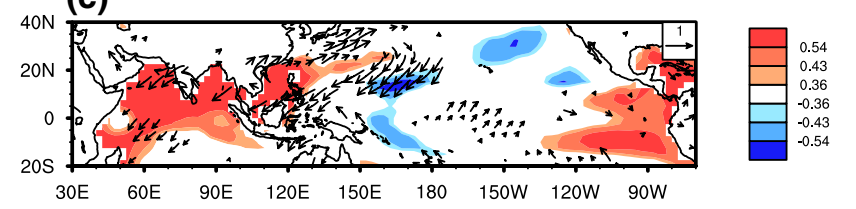

(e) $\mathrm{PC} 1$
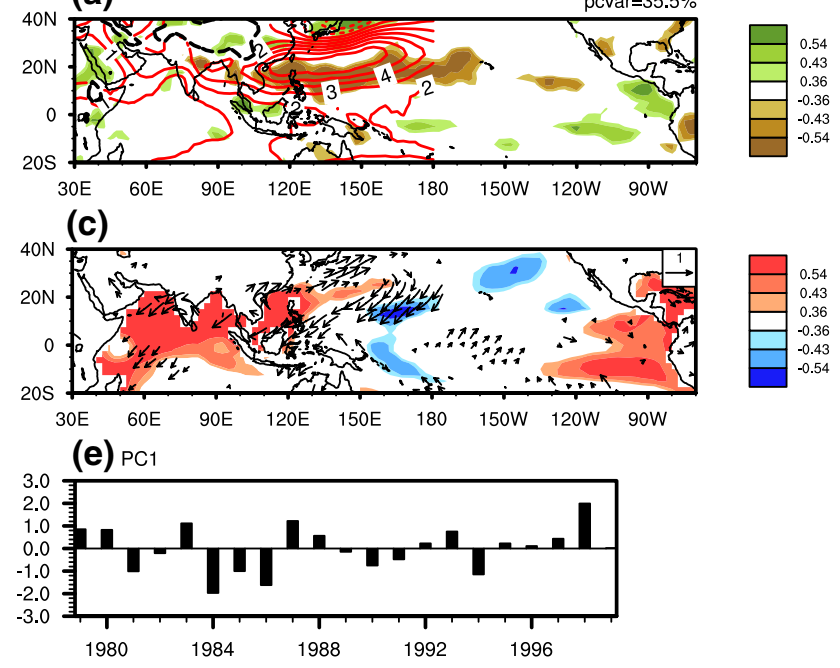

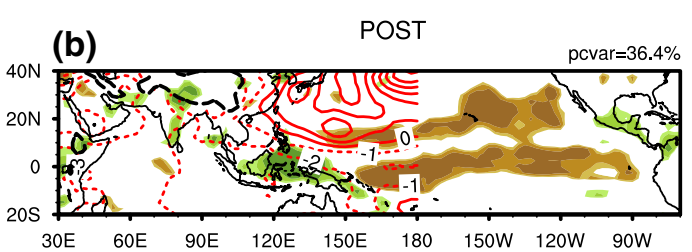

(d)
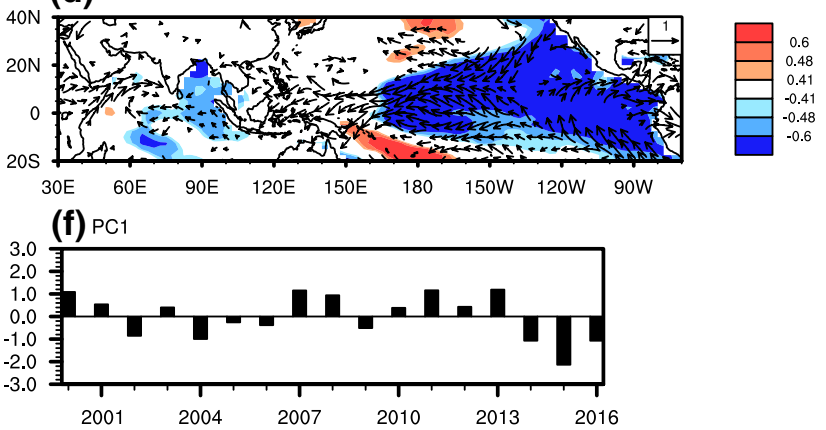

Fig. 6 The EOF-1 mode during 1979-1999 (left-side panels of a, c, e) and 2000-2016 (right-side panels of b, d, f). Panels a (b), c (d) and e (f) are the same as in Fig. $5 \mathbf{a ~ ( b ) , ~ c ~ ( d ) ~ a n d ~ e ~ ( f ) , ~ r e s p e c t i v e l y , ~ b u t ~ f o r ~ r e s u l t s ~ b a s e d ~ u p o n ~ t h e ~ E O F - 1 ~ m o d e ~ f o r ~ t h e ~ p e r i o d ~ o f ~ 1 9 7 9 - 1 9 9 9 ~ ( 2 0 0 0 - 2 0 1 6 ) ~}$

WPSHI and EAJSI after the late 1990s. The CC is 0.57 during the PRE epoch (significant at 99\% confidence level), but decreases to -0.17 during the POST epoch, suggesting the drastic weakening of the relationship between the WPSH and the EAJS after the late 1990s.

Figure $8 \mathrm{a}, \mathrm{b}$ exhibit the regression of horizontal winds at $850 \mathrm{hPa}$ based upon the EAJS during the PRE and POST epochs, respectively. Before the late 1990s, associated with the anomalous EAJS, there is a significant anticyclonic anomaly over the WNP and a cyclonic anomaly over the Japan Sea, resembling the PJ pattern. Remarkable convergence locates over the region from the middle and lower reach of the Yangtze River Valley to South Japan. Therefore, the EAJS is significantly and negatively correlated with the precipitation over the WNP and positively correlated with the precipitation over the middle and lower reach of the Yangtze River Valley and South Japan (Fig. 8c). During the POST epoch, the relationship between WPSHI and EAJSI weakens, no significant anticyclone circulation anomaly is observed over WNP (Fig. 8b), and the connection between the EAJS and the precipitation over the WNP-EA also weakens, no remarkable precipitation anomalies are observed over the middle and lower reach of the Yangtze River Valley and WNP (Fig. 8d).

Previous studies have documented that the barotropic response, which acts as the results of the coupling of external mode and internal mode excited by the tropical WNP precipitation anomaly, is necessary for the meridional teleconnection over the WNP-EA (PJ/EAP pattern), because the barotropic response emanates from the tropics into the extratropics, enabling the tropical-extratropical teleconnection (Kato and Matsuda 1992; Wang and Xie 1996). The (a) EOF1

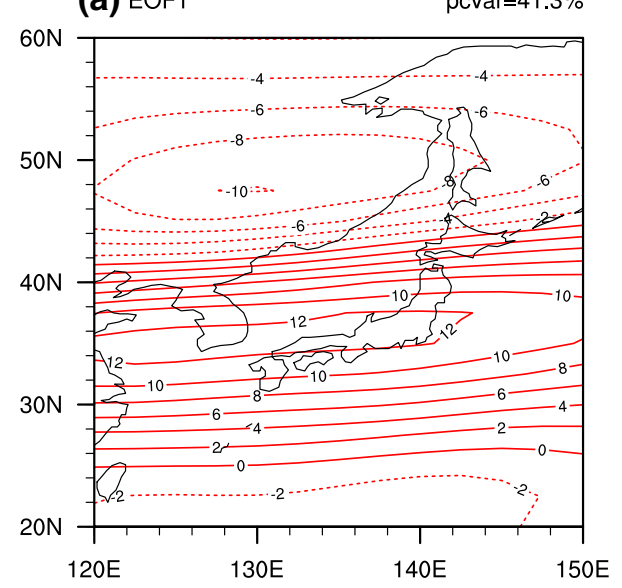

(b) PC1

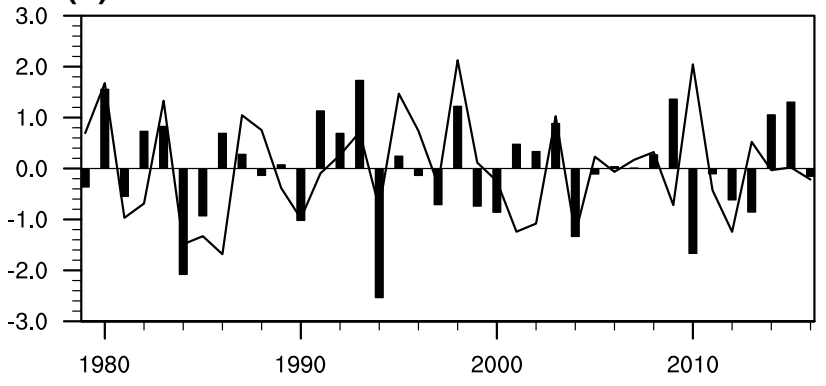

Fig. 7 a The first EOF mode of JJA zonal wind at $200 \mathrm{hPa}$ over $\left(20^{\circ}-60^{\circ} \mathrm{N}, 120^{\circ} \mathrm{E}-150^{\circ} \mathrm{E}\right)$ and $\mathbf{b}$ the corresponding PC1 during 1979-2016 (bars) which is defined as the East Asian jet stream index (EAJSI). The solid line is the normalized WPSHI during 1979-2016 
(a) PRE: Reg. UV850 aganist EAJS

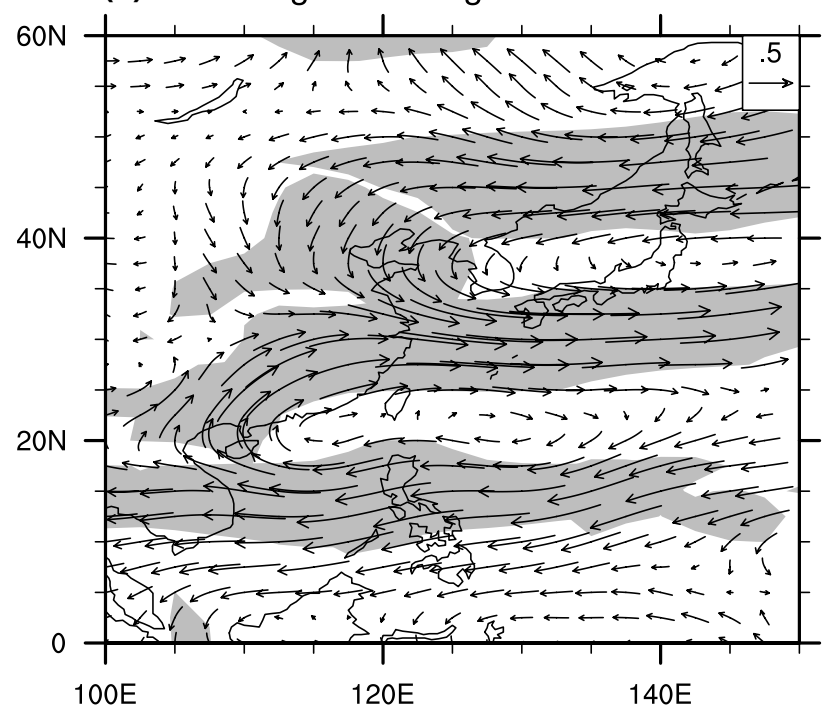

(b) POST: Reg. UV850 aganist EAJS

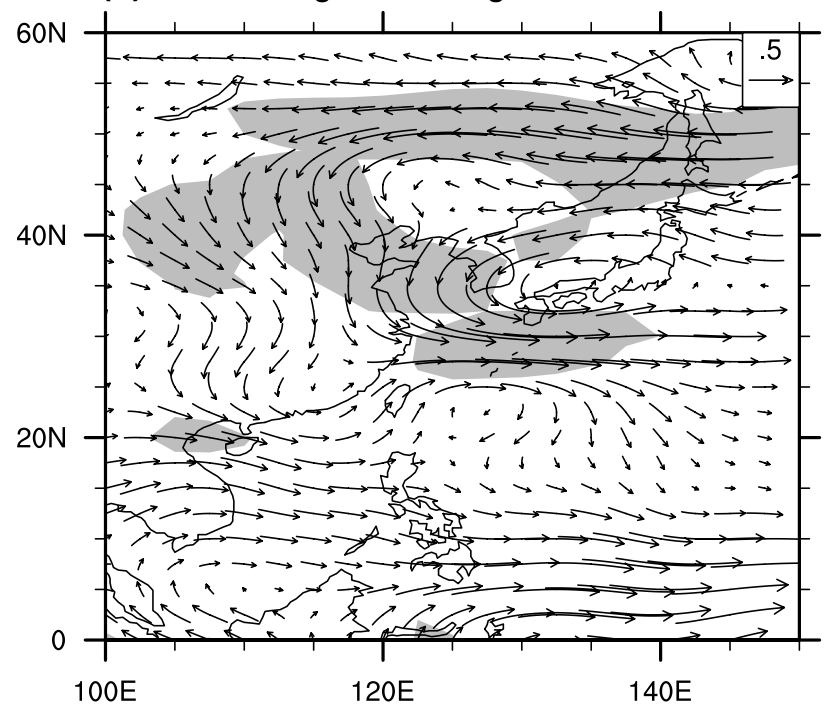

Fig. 8 Panels $\mathbf{a}$ and $\mathbf{b}$ are the regression of the horizontal winds at $850 \mathrm{hPa}\left(\mathrm{m} \mathrm{s}^{-1}\right)$ based upon EAJSI during 1979-1999 (a) and 2000-2016 (b). Panels $\mathbf{c}$ and $\mathbf{d}$ are the correlation coefficient between

WPSH and the EAJS have been viewed as two components of the meridional teleconnection over the WNP-EA (Huang et al. 2003; Lu 2004; Lu and Lin 2009). Therefore, the weakened relationship of the EAJS with the WPSH and the precipitation over WNP may contribute to the obscure low-level PJ pattern during POST epoch which can further leads to the weakened influence of the WPSH on the EASM.

In terms of the decadal shift of the WPSH influence on the ISM, it is interesting to notice that after removing the ENSO signals in WPSHI (WPSHI-OUT-ENSO), the CC between WPSHI-OUT-ENSO and the ISMRI is 0.27 (-0.03) during 2000-2016 (1979-1999). This result

\section{(c) PRE: Ccr between EAJS \& Precp}

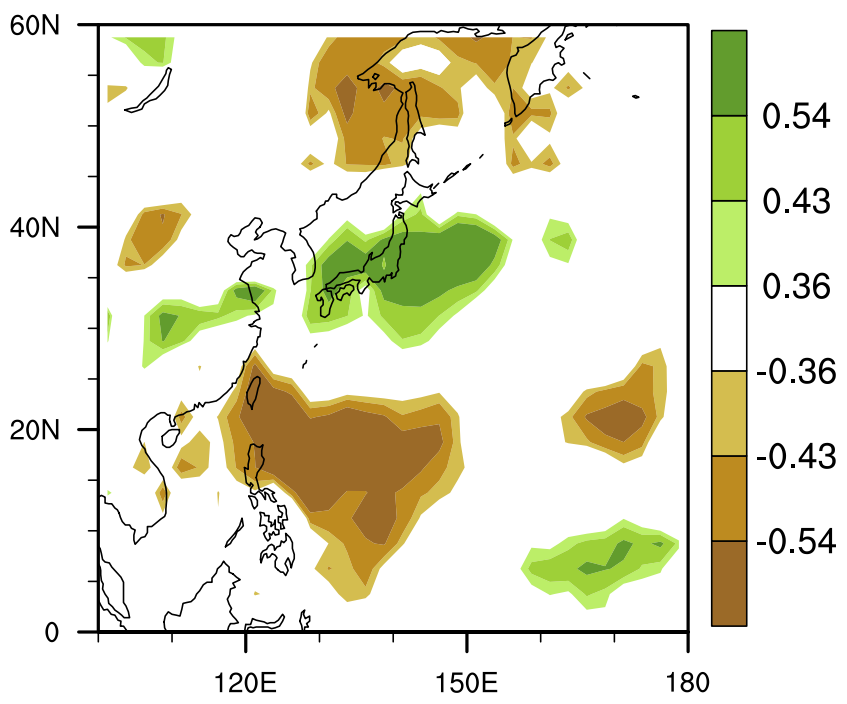

(d) POST: Ccr between EAJS \& Precp

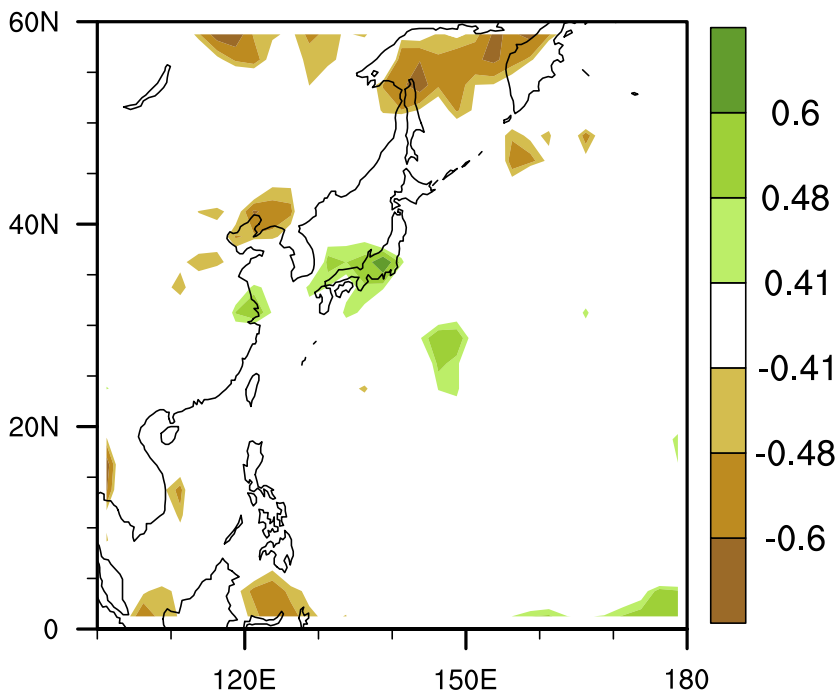

EAJSI and JJA precipitation (mm day ${ }^{-1}$ ) during 1979-1999 (c) and 2000-2016 (d). The light, medium and dark shading indicates significance at the 90,95 and $99 \%$ confidence level

implies that POST strengthened influence of the WPSH on the ISM derives quite possibly from strengthened impact of ENSO on the ISM. Actually, the CC between the Nino 3.4 index [SSTA averaged over $5^{\circ} \mathrm{S}-5^{\circ} \mathrm{N}, 170^{\circ} \mathrm{W}-120^{\circ} \mathrm{W}$ ] and the ISMRI is -0.16 during PRE epoch, but increases to -0.74 during POST epoch (significant at $99.9 \%$ confidence level). Figure 9 shows the regression map of velocity potential and divergent wind at 200 and $850 \mathrm{hPa}$ based upon the Nino 3.4 index during the PRE and POST epochs, respectively. Compared to the PRE epoch, the anomalous Indo-Pacific Walker circulation shifts westward 
(a) PRE: Reg. $\mathrm{CHI}$ and Div at $850 \mathrm{hPa}$ aganist Nino 3.4

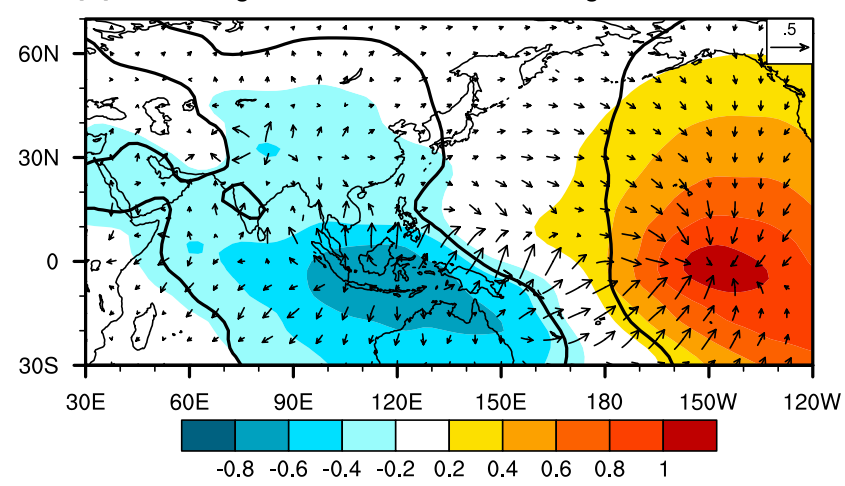

(b) POST: Reg. $\mathrm{CHI}$ and Div at $850 \mathrm{hPa}$ aganist Nino 3.4

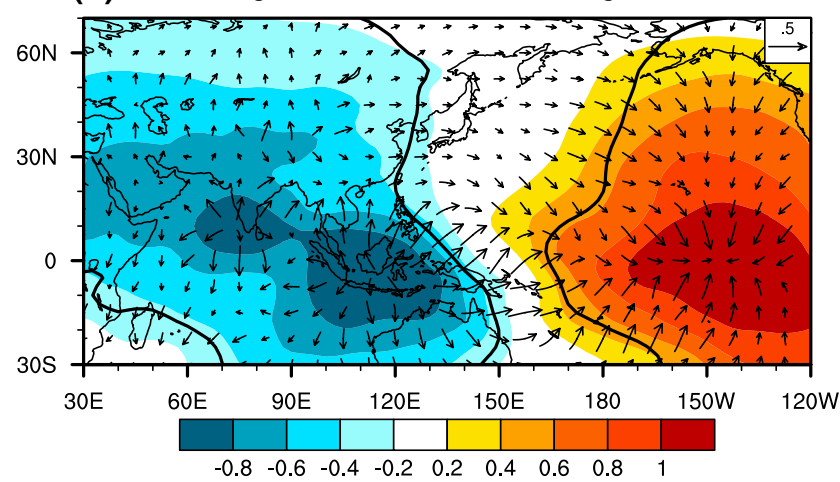

Fig. 9 Regression of JJA $850-\mathrm{hPa}$ velocity potential $\left(10^{6} \mathrm{~m}^{2} \mathrm{~s}^{-1}\right.$; shading) and divergent wind ( $\mathrm{m} \mathrm{s}^{-1}$; vectors) with respect to the Nino 3.4 index during 1979-1999 (a) and 2000-2016 (b). Panels c and d

remarkably in the POST epoch, with the low-level convergence (high-level divergence) center shifting from equatorial eastern Pacific to equatorial central Pacific and the low-level divergence (high-level convergence) center over the Maritime Continent in the PRE epoch extending northwestward to the Arabian Sea in the POST epoch (Fig. 9). This westward shifted Indo-Pacific Walker circulation may contribute to a strengthened relationship between ENSO and the ISM. Associated with the equatorial central Pacific cooling acting as the major forcing for the WPSH variability and the enhanced influence of ENSO on the ISM, the Indo-Pacific Walker circulation associated with WPSHI strengthens in the POST epoch, with the enhanced lower tropospheric divergence (upper tropospheric convergence) over equatorial central Pacific and enhanced lower tropospheric convergence (upper tropospheric divergence) over the Arabian Sea and Maritime Continent (Fig. 10). Therefore, we suggest that the strengthened influence of the WPSH on the ISM during the POST epoch may be attributed to the westward shifted Indo-Pacific Walker circulation. (c) PRE: Reg. $\mathrm{CHI}$ and Div at $200 \mathrm{hPa}$ aganist Nino 3.4

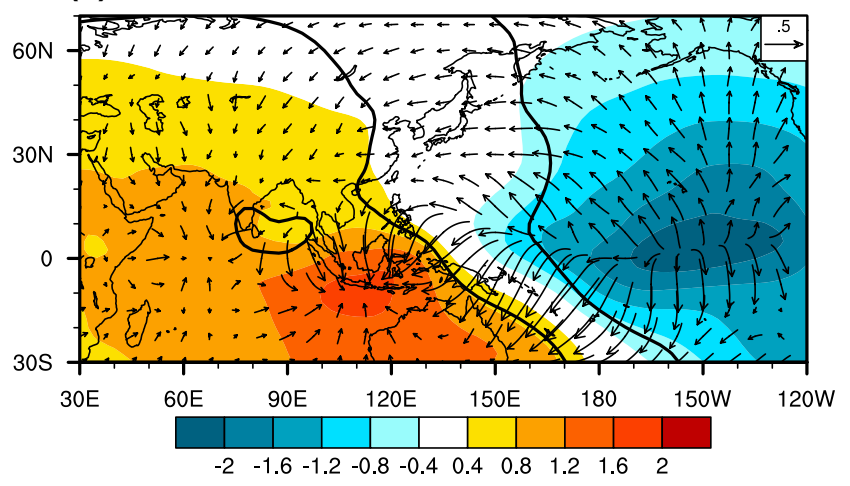

(d) POST: Reg. $\mathrm{CHI}$ and Div at $200 \mathrm{hPa}$ aganist Nino 3.4

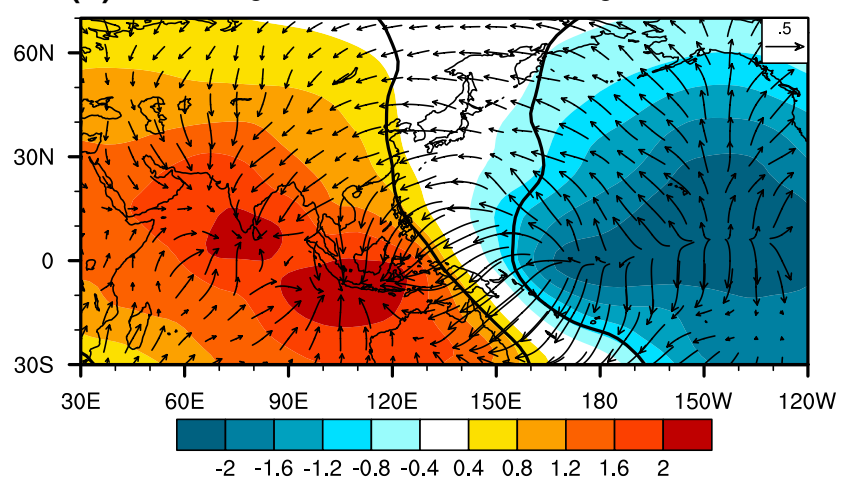

are the same as in Panels a and $\mathbf{b}$, respectively, but for $200 \mathrm{hPa}$. The thick line indicates the significant at the $95 \%$ confidence level

\section{Discussion}

In this section, we discuss the root cause of the decadal change of the low-level Asian-Western Pacific circulation, which are dominated by two modes during the 1979-2016: The Atmosphere-Ocean interaction (AOI) mode (EOF 1) and the central Pacific warming/cooling forced (CPF) mode (EOF2) (Fig. 5). The AOI mode does not have fundamentally change across the entire period. But the CPF mode has been enhanced and becomes the leading mode in POST epoch. Therefore, the decadal change of the low-level AsianWestern Pacific must arise from the increased CP SST forcing during the POST epoch.

The above assertion is consistent with observed decadal change of the ENSO properties. Canonical El Niño has a warming center in the eastern Pacific (EP), but in recent decades, El Niño warming center tends to occur more frequently in the central Pacific (CP). Since the late 1990s the standing CP El Nino becomes a dominant mode in the Pacific (Xiang et al. 2012).

With this decadal shift in the type of El Nino events, the anomalous Indo-Pacific Walker circulation shifts westward 
(a) PRE: Reg. $\mathrm{CHI}$ and Div at $850 \mathrm{hPa}$ aganist WPSH

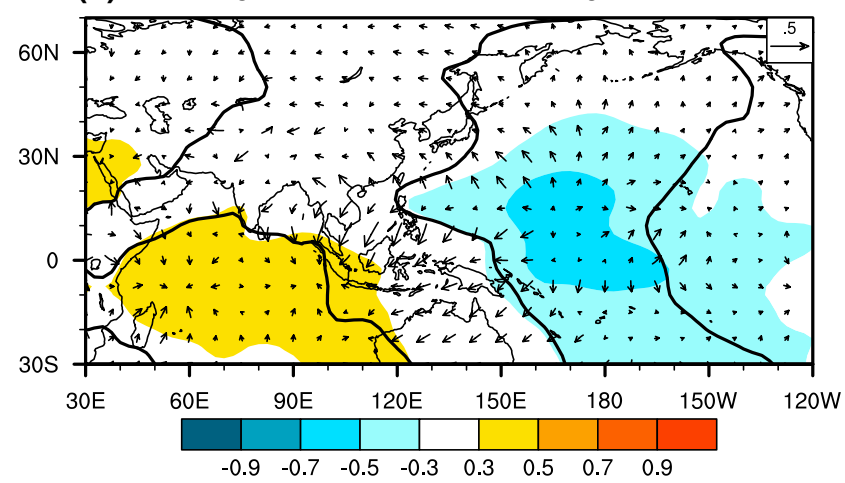

(b) POST: Reg. $\mathrm{CHI}$ and Div at $850 \mathrm{hPa}$ aganist WPSHI

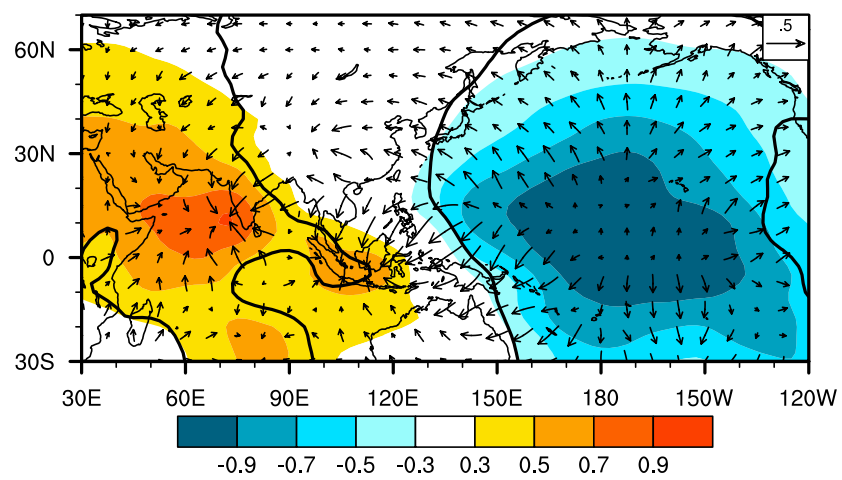

Fig. 10 Same as in Fig. 9, but with respect to the WPSHI

remarkably in the POST epoch (Kumar et al. 2006), which favors the WPSH influence the ISM. Meanwhile, there is an anomalous Walker circulation over the Maritime Continent and equatorial central Pacific, which can weaken the vertical shear over the WNP (figure not shown). The weakened vertical shear is unfavorable for the coupling of external mode and internal mode excited by the tropical WNP precipitation anomaly and results in non-significant barotropic response (Kasahara and Silva Dias 1986; Lu 2004; Lin et al. 2010), thus the PJ pattern weakens during the POST epoch. With the absence of the PJ pattern, the WPSH's influence on the EASM is obscure after the late 1990s.

The causes of the decadal change of the ENSO properties have been a debating issue. Global warming has been blamed for the westward shift of maximum warming as well as more frequent occurrence of CP El Nino (Yeh et al. 2009). However, since the late 1990s, the epochal mean trade winds have strengthened and the equatorial thermocline slope has increased, contrary to the global warming-induced weakening trades and flattening thermocline. Xiang et al. (2012) proposed that the recent predominance of CP El Nino arises from a dramatic decadal change characterized by a grand La Nin a-like background pattern and strong divergence in the CP atmospheric boundary layer. After the late 1990s, (c) PRE: Reg. $\mathrm{CHI}$ and Div at $200 \mathrm{hPa}$ aganist WPSHI

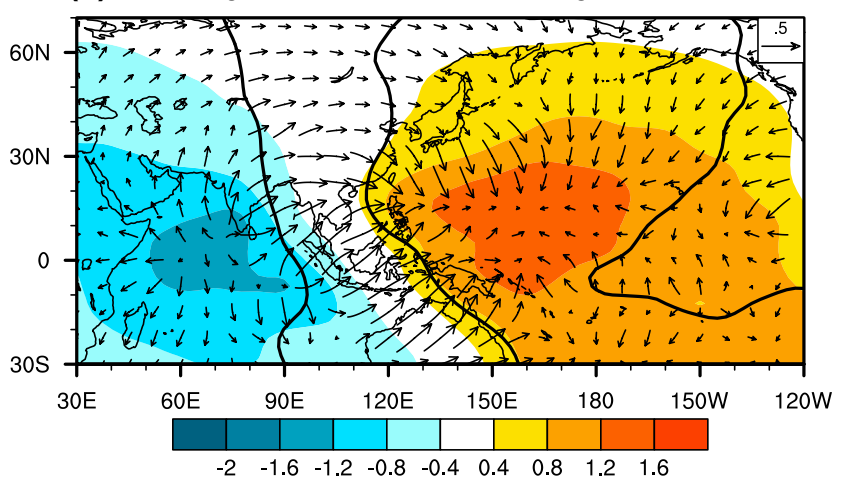

(d) POST: Reg. CHI and Div at $200 \mathrm{hPa}$ aganist WPSHI

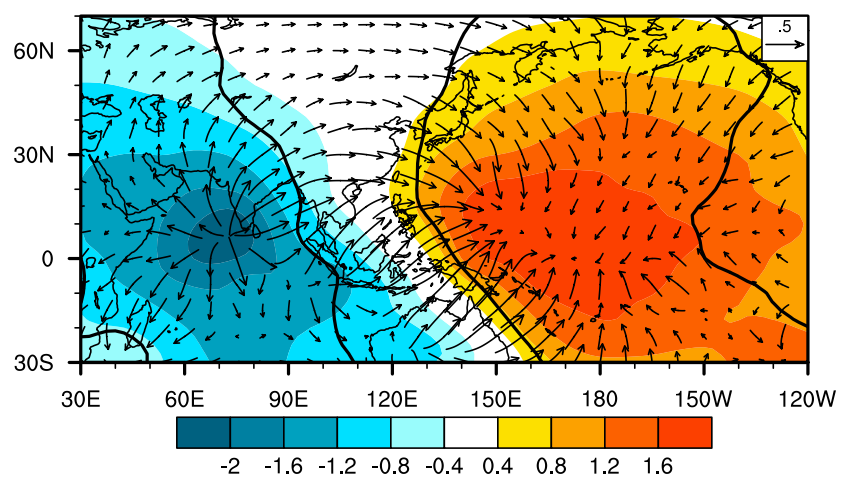

the anomalous mean $\mathrm{CP}$ wind divergence tends to weaken the anomalous convection and shift it westward from the underlying SST warming due to the suppressed low-level convergence feedback.

\section{Summary}

We find that after the late 1990s the spatial pattern of the primary EOF mode of H850 over the Asian-Australian monsoon domain has changed, leading to a decadal change of the WPSH's influence on Asian summer monsoon.

Prior to the 1999 (1979-1999), the first leading empirical orthogonal function mode (EOF-1) of the low-level Asian summer circulation, which is mainly affected by positive atmosphere-ocean feedback over Indo-Pacific warm pool oceans, features an intense high pressure system extending from the western Pacific to the Indian ocean and a PJ pattern over East Asian coast. With this spatial structure, the WPSH shows significant influence on the East Asian summer monsoon, but none on the Indian summer monsoon.

After the 1999 (2000-2016), the equatorial central Pacific cooling/warming becomes the major forcing, which shifts the Indo-Pacific Walker circulation westward and makes 
the EOF-1 mode of the low-level Asian summer circulation change to a dipole pattern with a high pressure system over the western Pacific and a low pressure system over the Indian Ocean. This changed EOF-1 mode favors the WPSH closely connected with the Indian summer monsoon. Meanwhile, with the obscure relationship between the EAJS and the WPSH and the absence of the PJ pattern, the WPSH's influence on the EASM becomes weaker after the late 1990s.

The decadal change of the primary low-level Asian-Western Pacific circulation is believed to arise from the increased CP SST forcing during the POST epoch. This assertion is also consistent with the observed decadal change of the ENSO properties: Since the late 1990s the standing CP El Nino becomes a dominant mode in the Pacific (Xiang et al. 2012), which is in association with strengthened epochal mean trade winds and increased $\mathrm{CP}$ wind divergence. The latter tends to shift anomalous convection and associated Walker cell westward.

The present study presents evidence that the WPSH not only affects EASM, but also the ISM. The ways by which WPSH intensifies and affects ISM and EASM involve two major mechanisms. One is the atmosphere-ocean interaction (AOI) between the WPSH and underlying anomalous SST dipole over the Indian-western Pacific warm pool ocean, and the other is the central Pacific SST anomalies. The AOI plays a main role during the El Nino/La Nina decaying summer in changing EA subtropical frontal rainfall, while the $\mathrm{CP}$ forcing acts during developing El Nino/La Nina summers to affect Indian summer rainfall. The results suggest that the two mechanisms are regulated by planetary scale background circulation and could have interdecadal changes.

In recent decades, PDO has changed from a positive phase to a negative phase after the late 1990s. Influences of the recent negative phase of PDO on the decadal change of Asian summer climate have been studied. For example, Zhu et al. (2015) have examined contributions of the negative phase of PDO after the late 1990s to the summer rainfall anomalies over East Asia by using numerical model experiments. Does the changed PDO phase contribute to the decadal shift of the WPSH's influence on the Asian summer climate? With the help of Yali Zhu and Jiehua Ma for offering their experiments' outputs, we investigate the spatial pattern of the EOF1 mode in modeling 40 years outputs for negative-PDO experiment and control experiment, respectively, and compare their differences. It is clear that the anomalies on the difference map of model experiments are opposite with those on the difference map of the two epochs in NCEP2 (figure not shown). Therefore, the PDO may not be the main direct reason for the decadal shift of the WPSH's influence on Asian summer climate (more designed details of model experiment can be seen in Zhu et al. 2015). It is possible that the PDO may contribute to the changed SSTA forcing for the WPSH variability and shows its indirect influence on the decadal shift of the WPSH's influence on Asian summer climate. However, it remains to be confirmed by further analysis in the future.

In general, the mechanisms that are possibly responsible for the decadal shift of the WPSH influence, remain to be confirmed. Further analysis based on more quantitative diagnose, as well as the state-of-the-art climate models, is needed in future work.

Acknowledgements This work was supported by National Natural Science Foundation of China (Grant Nos. 41505055, 41475039, 41420104002 and 41371209), the NOAA/DYNAMO\# NA13OAR4310167, the Global Research Laboratory (GRL) Program from the National Research Foundation of Korea (Grant Nos. 2011-0021927) and Nanjing University of Information Science AND Technology Talent Start Foundation (2016r029). This is the SEOST publication XXXX, and ESMC publication 189. We are grateful to Yali Zhu and Jiehua Ma, and Zhiqing Xu for the helpful advice.

Open Access This article is distributed under the terms of the Creative Commons Attribution 4.0 International License (http://creativecommons.org/licenses/by/4.0/), which permits unrestricted use, distribution, and reproduction in any medium, provided you give appropriate credit to the original author(s) and the source, provide a link to the Creative Commons license, and indicate if changes were made.

\section{References}

Adler RF, Huffman GJ, Chang A, Ferraro R, Xie P, Janowiak J, Rudolf B, Schneider U, Curtis S, Bolvin D, Gruber A, Susskind J, Arkin $\mathrm{P}$ (2003) The version 2 global precipitation climatology project (GPCP) monthly precipitation analysis (1979-present). J Hydrometeor 4:1147-1167

Chang CP, Zhang Y, Li T (2000) Interannual and interdecadal variations of the East Asian summer monsoon and tropical Pacific SSTs. Part I: roles of the subtropical ridge. J Clim 13:4310-4325

Chung PH, Sui CH, Li T (2011) Interannual relationships between the tropical sea surface temperature and summertime subtropical anticyclone over the western North Pacific. J Geophys Res Atmos 116:1016-1022

Ding YH (1994) The summer monsoon in East Asia. Monsoons over China. Kluwer, Dordrecht, pp 1-9

Du Y, Xie S-P, Huang G, Hu K (2009) Role of air-sea interaction in the long persistence of El Niño-induced North Indian Ocean warming. J Clim 22:2023-2038

Fan K, Wang H, Choi Y-J (2008) A physically-based statistical forecast model for the middle-lower reaches of the Yangtze River Valley summer rainfall. Chin Sci Bull 53:602-609

Feng J, Wang L, Chen W (2014) How does the East Asian summer monsoon behave in the decaying phase of El Niño during different PDO phases? J Clim 27:2682-2698

He C, Zhou T (2015) Decadal change of the connection between summer western North Pacific subtropical high and tropical SST in the early 1990s. Atmos Sci Lett 16:253-259

He C, Zhou T, Wu B (2015) The key oceanic regions responsible for the interannual variability of the western North Pacific subtropical high and associated mechanisms. J Meteorol Res 29:562-575

Hoskins BJ (1996) On the existence and strength of the summer subtropical anticyclones. Bull Am Meteorol Soc 77:1287-1292 
Huang Y, Li X (2015) The interdecadal variation of the Western Pacific subtropical high as measured by $500 \mathrm{hPa}$ Eddy geopotential height. Atmos Ocean Sci Lett 8:371-375

Huang R, Sun F (1992) Impacts of the tropical western Pacific on the East Asian summer monsoon. J Meteorol Soc Jpn 70:243-256

Huang R, Wu Y (1989) The influence of ENSO on the summer climate change in China and its mechanism. Adv Atmos Sci 6:21-32

Huang Y, Wang H, Zhao P (2013) Is the interannual variability of the summer Asian-Pacific oscillation predictable? J Clim 26:3865-3876

Huang R, Zhou L, Chen W (2003) The progresses of recent studies on the variabilities of the East Asian Monsoon and their causes. Adv Atmos Sci 20:55-69

Huang Y, Wang H, Fan K, Gao Y (2015) The western Pacific subtropical high after the 1970s: westward or eastward shift? Clim Dyn 44:2035-2047

Jiang D, Wang H (2005) Natural interdecadal weakening of East Asian summer monsoon in the late 20th century. Chin Sci Bull 50:1923-1929

Jin D, Hameed SN, Huo L (2016) Recent changes in ENSO teleconnection over the Western Pacific impacts the Eastern China precipitation dipole. J Clim 29:7587-7598

Kanamitsu M, Ebisuzaki W, Woollen J, Yang S-K, Hnilo JJ, Fiorino M, Potter GL (2002) Ncep-doe amip-ii reanalysis (r-2). Bull Am Meteorol Soc 83:1631-1643

Kasahara A, Silva Dias PL (1986) Response of planetary waves to stationary tropical heating in a global atmosphere with meridional and vertical shear. J Atmos Sci 43:1893-1911

Kato T, Matsuda Y (1992) External mode induced by tropical heating in the basic flow with vertical shear and its propagation. J Meteor Soc Japan 70:1057-1070

Kumar KK, Rajagopalan B, Hoerling M, Bates G, Cane M (2006) Unraveling the mystery of Indian monsoon failure during El Niño. Science 314:115-119

Lau KM, Li MT (1984) The monsoon over East Asia and its global association-a survey. Bull Am Meteor Soc 65:116-125

Lau KM, Kim KM, Yang S (2000) Dynamical and boundary forcing characteristics of regional components of the Asian summer monsoon. J Clim 13:2461-2482

Lee JY, Wang B, Seo KH, Ha KJ, Kitoh A, Liu J (2015) Effects of mountain uplift on global monsoon precipitation. Asia Pac J Atmos Sci $51: 275-290$

Li S, Lu J, Huang G, Hu K (2008) Tropical Indian Ocean basin warming and East Asian summer monsoon: a multiple AGCM study. J Clim 21:6080-6088

Lin Z, Lu R, Zhou W (2010) Change in early-summer meridional teleconnection over the western North Pacific and East Asia around the late 1970s. Int J Climatol 30:2195-2204

Lu R (2004) Associations among the components of the East Asian summer monsoon system in the meridional direction. J Meteorol Soc Jpn 82:155-165

Lu R, Dong B (2001) Westward extension of North Pacific subtropical high in summer. J Meteorol Soc Jpn 79:1229-1241

Lu R, Lin Z (2009) Role of subtropical precipitation anomalies in maintaining the summertime meridional teleconnection over the Western North Pacific and East Asia. J Clim 22:2058-2072

Lu R, Hong XW, Li XY (2016) Asymmetric association of rainfall and atmospheric circulation over East Asia with anomalous rainfall in the tropical western North Pacific in summer. Atmos Ocean Sci Lett. doi: 10.1080/16742834.2016.1161489

Miyasaka T, Nakamura H (2005) Structure and formation mechanisms of the Northern Hemisphere summertime subtropical highs. J Clim 18:5046-5065

Nitta T (1987) Convective activities in the tropical western Pacific and their impact on the Northern Hemisphere summer circulation. J Meteorol Soc Jpn 65:373-390
Rodwell MJ, Hoskins BJ (2001) Subtropical anticyclones and summer monsoons. J Clim 14:3192-3211

Smith TM, Reynolds RW, Peterson TC, Lawrimore J (2008) Improvements to NOAA's historical merged land-ocean surface temperature analysis (1880-2006). J Clim 21:2283-2296

Tao SY (1963) On the summer synoptic systems in the subtropics over China (in Chinese). Science Press, Beijing

Tao SY, Chen LX (1987) A review of recent research on the East Asian summer monsoon in China. Monsoon Meteorology, vol 7. Oxford University Press, New York, pp 60-92

Wang HJ (2001) The weakening of the Asian monsoon circulation after the end of 1970s. Adv Atmos Sci 18:376-386

Wang B, Fan Z (1999) Choice of South Asian summer monsoon indices. Bull Am Meteorol Soc 80:629-638

Wang B, Xie X (1996) Low-frequency equatorial waves in vertically sheared zonal flow. Part I: stable waves. J Atmospheric Sci 53:449-467

Wang B, Wu R, Fu X (2000) Pacific-East Asian teleconnection: how does ENSO affect East Asian climate? J Clim 13:1517-1536

Wang B, Wu R, Lau KM (2001) Interannual variability of the Asian summer monsoon: contrasts between the Indian and the Western North Pacific-East Asian monsoons. J Clim 14:4073-4090

Wang B, Wu R, Li T (2003) Atmosphere-warm ocean interaction and its impacts on Asian-Australian monsoon variation. J Clim 16:1195-1211

Wang B, Yang J, Zhou T, Wang B (2008) Interdecadal changes in the major modes of Asian-Australian monsoon variability: strengthening relationship with ENSO since the late 1970s. J Clim 21:1771-1789

Wang B, Xiang B, Lee JY (2013) Subtropical High predictability establishes a promising way for monsoon and tropical storm predictions. Proc Natl Acad Sci 110:2718-2722

Wu GX, Liu YM (2003) Summertime quadruplet heating pattern in the subtropics and the associated atmospheric circulation. Geophys Res Lett. doi:10.1029/2002GL016209

Xiang B, Wang B, Ding Q, Jin FF, Fu X, Kim HJ (2011) Reduction of the thermocline feedback associated with mean SST bias in ENSO simulation. Clim Dyn 39:1-18

Xiang B, Wang B, Li T (2012) A new paradigm for the predominance of standing Central Pacific warming after the late 1990s. Clim Dyn 41:327-340

Xie SP, Hu K, Hafner J, Tokinaga H, Du Y, Huang G, Sampe T (2009) Indian Ocean capacitor effect on Indo-Western Pacific climate during the summer following El Niño. J Clim 22:730-747

Xu Z, Fan K, Wang H (2015) Decadal variation of summer precipitation over china and associated atmospheric circulation after the late 1990s. J Clim 28:4086-4106

Yang J, Liu Q, Xie SP, Liu Z, Wu L (2007) Impact of the Indian Ocean SST basin mode on the Asian summer monsoon. Geophys Res Lett 34:L02708. doi:10.1029/2006GL028571

Ye DZ, Gao YX (1979) Meteorology over Tibetan. Plateau Science Press, Beijing, p 278

Ye DZ, Wu GX (1998) The role of the heat source of the Tibetan Plateau in the general circulation. Meteorol Atmos Phys 67:181-198

Yeh S-W, Kug J-S, Dewitte B, Kwon M-H, Kirtman B, Jin F-F (2009) El Niño in a changing climate. Nature 461:511-514. doi:10.1038/ nature 08316

Yim S-Y, Jhun J-G, Yeh S-W (2008) Decadal change in the relationship between east Asian-western North Pacific summer monsoons and ENSO in the mid-1990s. Geophys Res Lett. doi:10.1029/200 8GL035751

Zhou B, Wang H (2006) Relationship between the boreal spring Hadley circulation and the summer precipitation in the Yangtze River valley. J Geophys Res Atmos. doi:10.1029/2005JD007006 
Zhu Y, Wang H, Zhou W, Ma J (2011) Recent changes in the summer precipitation pattern in East China and the background circulation. Clim Dyn 36:1463-1473
Zhu Y, Wang H, Ma J, Wang T, Sun J (2015) Contribution of the phase transition of Pacific Decadal Oscillation to the late 1990s' shift in East China summer rainfall. J Geophys Res Atmos 120:8817-8827 